\title{
Development and Testing of Adaptive Vehicle Speed Monitoring System integrated with Alcoholic Detector for Public Buses: A case of Tanzania
}

\author{
Farhan Ramju \\ Department of Communication \\ Science and Engineering \\ Nelson Mandela African \\ Institution of Science and \\ Technology (NM-AIST), \\ Arusha, Tanzania.
}

\author{
Ramadhani S. Sinde \\ Department of Communication \\ Science and Engineering \\ Nelson Mandela African \\ Institution of Science and \\ Technology (NM-AIST), \\ Arusha, Tanzania.
}

\author{
Shubi Kaijage \\ Department of Communication \\ Science and Engineering \\ Nelson Mandela African \\ Institution of Science and \\ Technology (NM-AIST), \\ Arusha, Tanzania.
}

\begin{abstract}
Road accidents are the serious humanity and public health issue in Tanzania. The problem is increasing day by day. Apart from the loss of many lives, the effect of the road crashes on the country's economy is massive. In Tanzania Human factors is the main contribution of major road crashes while over-speeding and drinking driving is one of the accelerating factors to the increase of road casualties. Existing measures to limit these problems have been unsuccessful to diminish the road accidents thus only use of handheld devices such as the speed radar gun and breath analyzer is applicable during inspection on the road or check points. Since these devices are not automatic in the sense that they would need to be operated manually by the Traffic Police, they lack the continuous monitoring of speed and therefore their efficiency in speed detection is low. To address these challenges, an adaptive vehicle speed monitoring system integrated with alcohol detector is utmost important. This chapter attempts to develop an effective solution for vehicle speed monitoring and alcohol detection on a real time basis. The main objective of this paper is to develop an adaptive vehicle speed monitoring integrated with an alcoholic detection system able to monitor the vehicle speed into defined speed limits and driver's alcoholic content (Blood Alcoholic Content) during the journey on the road. The system consists of GPS module that measures the distance and calculates the accurate speed of moving objects and also provides a location in term of latitude and Longitude, sensor nodes to measure the level of alcoholic content through breath, Arduino controller also used to drive the operation of the system. The system is integrated with LCD display for the driver and GSM network to send the message to the database to be stored for future uses and constantly updating the law enforcers (traffic policies) on what is going on in the roads and take prompt action in case of misbehaving. The system will help most of traffic police in finding out driver's behavior on the road and also public buses that are daily victims of road accidents results due to the Human factors.
\end{abstract}

\section{General Terms}

Over speed,Blood Alcohol Concentration,SQL Server, Reverse Geocoding.

\section{Keywords}

LCD,GSM,GPS,MQ-3,NMEA,Arduino UNO rev3,BAC,SMS

\section{INTRODUCTION}

In Tanzania Road Transportation is mainly used and easy way of travelling and moving goods by many Tanzanians. Road traffic represents 70 per cent of freight and 90 percent of passenger transport market shares in Tanzania. Road transport is vital to the socioeconomic growth of Tanzania. Although it plays a major part in our society, but road sector undergoes some of the challenges. Road crashes are the biggest problem that our country is facing; many Tanzanian's have lost their lives and valuable properties. The World Health Organization states that road crashes are the ninth factor worldwide for causing deaths. If the situation is not reversed, road crashes will rise to the third place in causing deaths by the year 2020 [1]. It's estimated between 2010 and 2012, 3,381 persons lost their lives in bus crashes in Tanzania, accounting for approximately $29 \%$ of the 11,512 road crash deaths in Tanzania during this period via all modes of transport [2]. Recent statistics show that between 2009 and 2012 only about $10 \%$ of crashes are due to environmental factors (i.e. weather, road conditions) while the grand majority $90 \%$ of bus crashes are caused by human factors, including reckless driving, speed, drink driving and vehicle negligence $[2,3]$. There is a need of technological involvements in increasing road safety and lessening the number of people who die from road accidents each year. In Tanzania most of the road accidents are caused due to reckless driving, over speeding, drinking driving and overloading [3]. This paper is focusing on the factors related to human, speeding and drinking driving particular. Over-speeding may result to loose of control of the vehicle and give a driver no time to make precise decisions. The crash impact due to higher speeding is more destructive and therefore increases the severity of the damage [4]. Either way, alcohol results in impairment which increases the likelihood of a crash since it produces a poor judgment, increased reaction time, lower awareness and decreased visual insight. However, the effects become progressively worse as the BAC increases [1]. The amount of alcohol that is contained within the bloodstream can be measured by testing a small sample of blood or urine, or through analysis of exhaled breath. Not only do judgment and reaction time suffer, but vision also fades. Apart from its direct impact on crash outcomes, alcohol is believed to affect other aspects of driver safety, such as seatbelt wearing, helmet use, and speed choice. Also, The Tanzania Government has formulated a number of initiatives in trying to reduce the problem of road crashes, discourage the use of alcoholic drinks while driving by providing education to the community and also by 
installing placards along the road with different messages about the effect of drunkenness while driving. This is one of the better efforts to reduce accidents, but it depends on the willingness of the driver and therefore may not be much more effective. Despite the fact that drunk driving is a serious problem, its detection has been so far relying on visual observations by patrol officers. Some of the measures have been addressed to reduce these road crashes result due to the Human factors but still there are some challenges. Traffic police officers when on patrols or at check points uses a speed radar gun for monitoring speed of vehicles and alcohol breath analyzer, Speed, Radar gun is a hand held device that operates in the form of sending a microwave signal that produced by gun and hit the target and return back then calculate the speed and breath analyzer is the device that calculate the amount of alcohol within the bloodstream through analysis of exhaled breath is described in terms of BAC. These devices are not efficient due to the fact that one needs to hold them and direct towards the vehicles. Their exercise cannot be continuous and effective because the officers are human beings and can be tired during the monitoring exercise. Moreover, driver's tend to slow down when they approach the checkpoints or get alerted by fellow road users/driver's. Hence, one can realize that driver's tend to reduce speed only at the places where they expect to get monitored. Another case is during a bad weather condition which hinder a process of manual traffic police check-up. Due to various reasons mentioned here, the adaptive monitoring and control system which will monitor the speed of the vehicle throughout the journey and adapt the environment designed and hence the development and implementation of the system is particularly important and necessary. Recently, GPS have achieved a great potential for a widespread application such as vehicle speed measuring with precise location and heading. With the advent of GPS and the ubiquitous cellular network, real time vehicle tracking for better transport management has become possible [4]. The Global Positioning System (GPS) is based on a large number of satellites radiating microwave signals for picking up by GPS receivers to determine their current location [5]. Use of GPS integrated with microcontroller and sensors found to be an efficient method of measuring and monitoring of vehicle speed and driver's behavior on the road. The GPS has advantages as easy to navigate, works in all-weather condition and Low deployment cost [6]. Many researchers have done research on this area and many systems has developed and implemented. Intelligent Speed Adaptation (ISA) system is a GPS-based navigation system that installed in a vehicle in which the vehicle "knows" the speed limit and is capable of using that information to give feedback to the driver or limit maximum speed, vehicle itself would know its location and speed limit for that location from an on-board digital road map in which the speed limit for each link in the network had been encoded [7]. Another study made a use of ZigBee transmitter and transceiver used in which transmitter sends the speed limit and a receiver unit placed in vehicle receives the messages and sends to the microcontroller. When the speed of the vehicle nears the speed limit it displays the warning and if exceeds the limit, the microcontroller records the violated speed and time. The LCD displays the lane speed limit and shows the number of times, speed was violated. A GSM module sends a message to the nearest traffic personnel immediately after a violation occurs [8]. Another part of violation prevention, a researcher integrated MQ-3 alcoholic sensor with microcontroller as well as with the ignition systems circuit so as whenever alcohol is detected from breath, a microcontroller will command ignition system not to start the vehicle [9].

\section{MATERIAL AND METHODS USED}

An adaptive vehicle speed monitoring system integrated with alcoholic detector deployed using GPS and MQ-3 sensor has main three units; The On-Board Unit which is connecting GPS, sensor integrated with Arduino controller which information provided by sensing and remote devices that collect information of the vehicle position with speed and driver behavior on the road, Arduino is the heart of all the system that any information acquired by on board unit is provided to it to make decision, and any decision it makes is sent to a control centre through a communication link that will be provided at both ends, second unit is Data Storage Unit which is storing any information coming from on-board unit. The communication between these units is through Global System for Mobile Communications (GSM) which is third unit. All the information is sent to the Database in Short Message Service (SMS) form through GSM base Station to the intended destination.

\subsection{System Flow}

An adaptive vehicle speed monitoring system integrated with alcoholic detector is working under the following processes: the system starts by initializing all the settings of all equipment's on the on-board unit; GPS itself will determine its location and speed limit of the vehicle and find out where it's heading, it will acquire the vehicle speed and equalize with saved speed limit within that zone, and if moving vehicle speed is less than speed limit, no action will be taken else warning will be provided to reduce the speed with blinking red LED and LCD display to show current zone speed and moving speed. Microcontroller integrated with alcohol sensor placed inside the vehicle will interpret data and check if BAC measured from human breath is greater normal BAC limit, a warning will also provide using red blinking LED and display to alert stop driving else violation will be sent through GSM network to law enforcers. Violation information consists of vehicle ID, Location, time and date and event type (Over speed or BAC) is sent to the database and a nearest police post or check-up point in case of misbehaving.

Fig.1 below illustrates the conceptual model of an adaptive vehicle speed monitoring system integrated with alcoholic detector.

The system work flow above can be summarized in the following steps:

1. Initialize all the settings for all the devices on on-board unit

2. GPS and alcohol sensor read Vehicle speed and BAC on human breath respectively at predefined intervals,

3. The data read is equalized with limit values stored in the microcontroller,

4. Warning is given to a driver for defined interval to reduce speed or not drive at all if a high BAC or over speed is detected, else the process is repeated,

5. GPS will find the current location with the time and date of vehicle if any violation is detected,

6. Violation information on SMS will be sent via GSM to update the law enforcers (traffic policies),

7. Same SMS also sent to a central database for recording violation. This process is repeated at the specified time intervals. 


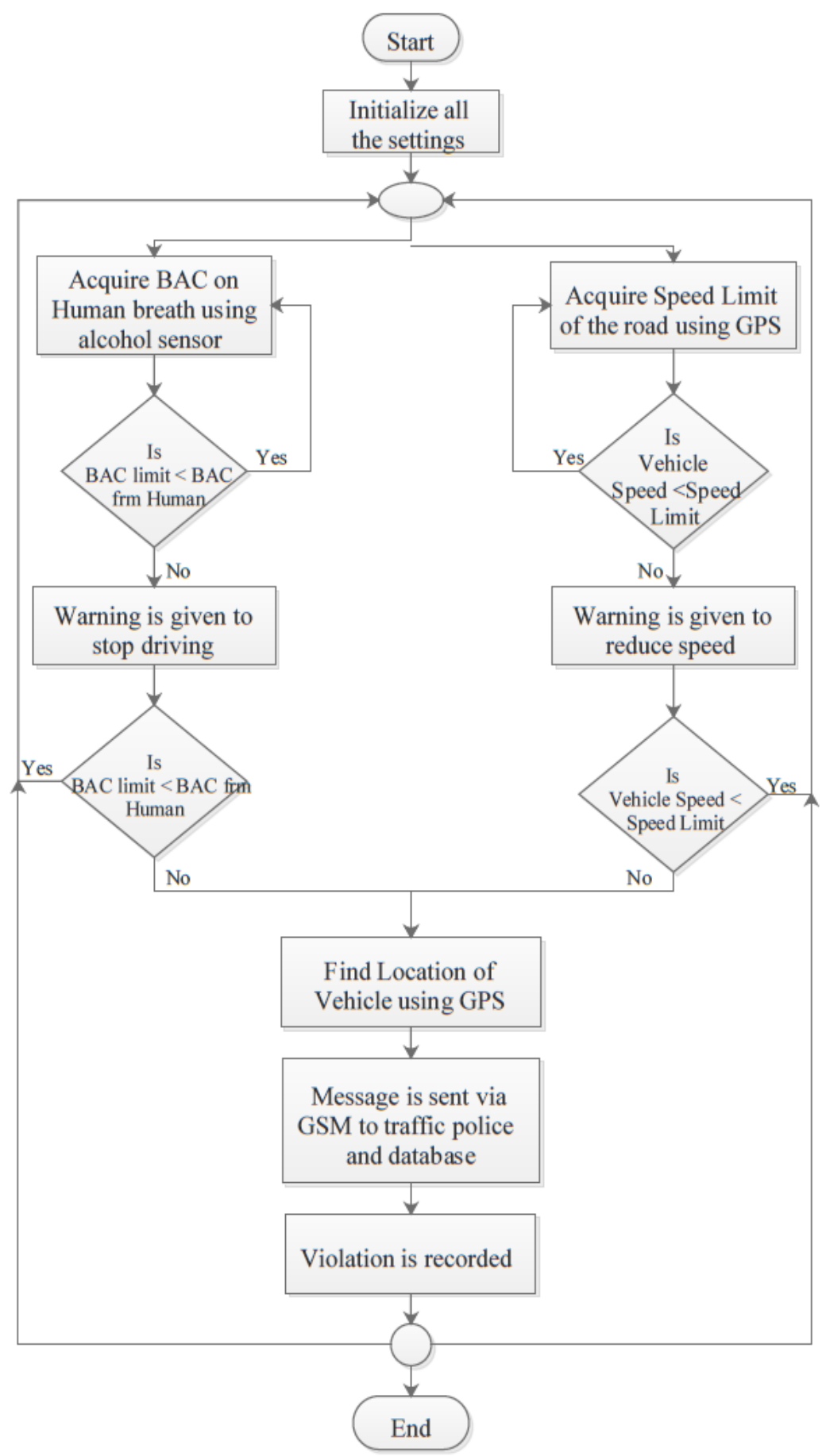

Figure 1: System work flow diagram

During the design of the adaptive vehicle speed monitoring system integrated with alcoholic detector, the hardware part was categorized into two parts, on-board part and data storage part.

\subsection{The on-board part}

It's a part of the system that resides into a vehicle, driver and vehicle behavior is monitored through this part as all the devices are integrated to form an on-board system for vehicle speed and drink driving monitoring.

\subsubsection{MQ-3 Alcohol Sensor}

This is an alcohol sensor is suitable for detecting alcohol concentration on the human breath. It has a high sensitivity and fast response time. The sensor provides an analog resistive output based on alcohol concentration. The drive circuit is very simple; all it needs is one resistor of $200 \mathrm{~K} \Omega$. It's a simple drive circuit of $5 \mathrm{~V}$ DC with analog output. It is a low cost, Stable and Long Life. As shown in Fig. 2 below, it has 6 pins, the cover and the body. Even though it has 6 pins, only 4 of them are used, 2 of them are for the heating system and other 2 are for connecting power and ground. A little tube is placed inside the sensor. This tube is a heating system that is made of aluminium oxide and tin dioxide and inside of it there are heater coils, which practically produce the heat. Two pins are connected to the heater coils and others connect to the 
tube. The core system is the cube. Basically, it is an Alumina tube cover by $\mathrm{SnO} 2$, which is tin dioxide. And between them there is an Aurum electrode. Basically, the alumina tube and the coils are the heating system. If the coil is heated up, $\mathrm{SnO} 2$ ceramics will become the semi - conductor, so there are more movable electrons, which means that it is ready to make more current flow. Then, when the alcohol molecules in the air meet the electrode that is between alumina and tin dioxide, ethanol burns into acetic acid then more current is produced. So the more alcohol molecules there are the more current will be produced. Because of this current change, the different values from the sensor is obtained.

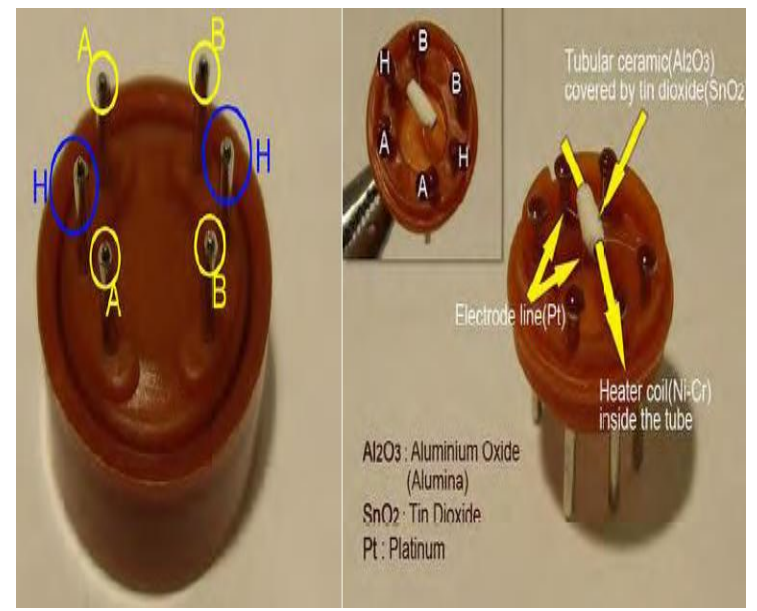

Figure 2: MQ-3 alcohol sensor

\subsubsection{Arduino UNO Rev3}

The Arduino board is a specially designed circuit board for programming and prototyping with Atmel microcontrollers. It's an open-source physical computing platform based on a simple microcontroller board, and a development environment for writing software for the board. It is a low-cost integrated circuit that contains memory, processing units, and input/output circuitry in a single unit. Figure 3 exhibit the Arduino UNO Rev3, it's a microcontroller board based on the ATmega328. +It has 14 digital input/output pins (of which 6 can be used as Pulse Width Modulation (PWM) outputs), 6 analog inputs, a $16 \mathrm{MHz}$ crystal oscillator, a USB connection, a power jack, an In Circuit Serial Programmer (ICSP) header, and a reset button. It contains everything needed to support the microcontroller; simply, it's connected to a computer with a USB cable or powered with AC-to-DC adapter or battery to get started. It has a very convenient power management and built-in voltage regulation. In addition, the operating voltage of the Arduino board is 5V DC, while recommending Input Voltage to be $7 \mathrm{~V}-12 \mathrm{~V}$ and the operating frequency is $16 \mathrm{MHz}$.

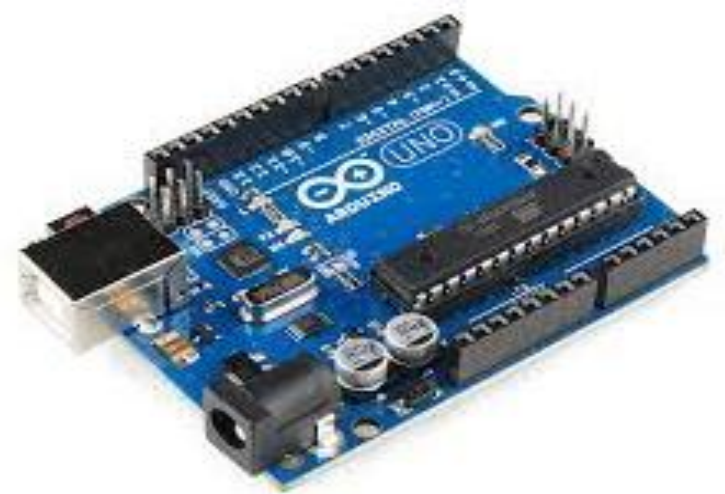

Figure 3: Arduino UNO Rev3- ATmega328

\subsubsection{GPS Module}

The Global Positioning System (GPS) is a global navigation satellite system which uses a constellation of between 24 and 32 Medium Earth Orbit satellites that transmit precise microwave signals that enable GPS receivers to determine their location, speed, direction, and time. These satellites are equipped with atomic clocks and send out radio signals as to the exact time and their location. These radio signals from the satellites are picked up by the GPS receiver. Once the GPS receiver locks onto four or more of these satellites, it can triangulate its location from the known positions of the satellites. Depicted below in fig. 19 the shield from Cytron Technologies. The Shield comes with a SKM53 GPS module on it. It's designed specially for Arduino UNO or CT-UNO. This shield provide UART pin selectors for user to utilize the software serial on Arduino for communication with GPS module. It comes with embedded GPS antenna, which enables high performance navigation in the most rigorous applications and solid fix even in harsh GPS visibility environments. The module has $-165 \mathrm{dBm}$ tracking sensitivity extends positioning coverage into place like urban canyons and dense foliage environment where the GPS was not possible before [10].

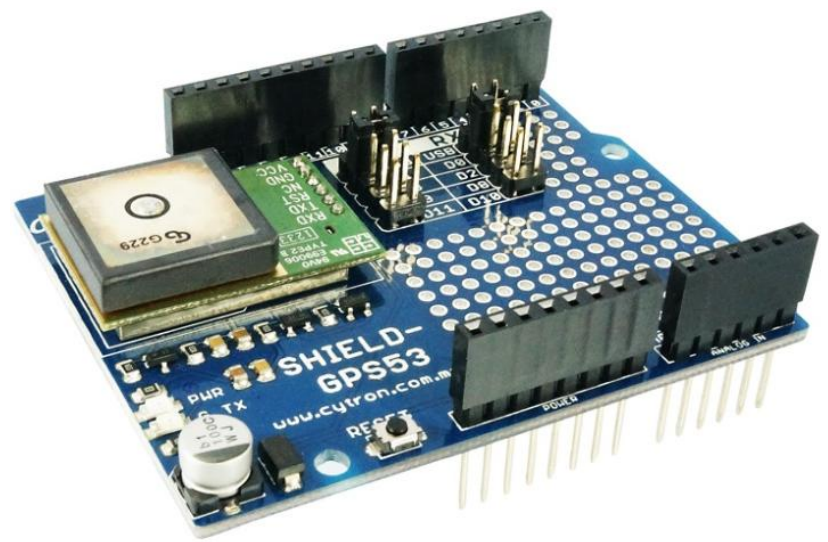

Figure 4: GPS receiver

\subsubsection{GSM Modem - SIM900A}

Global System for Mobile communications (GSM) is an open, digital cellular technology used for transmitting mobile voice and data services. GSM uses a variation of Time Division Multiple Access (TDMA) and is the most widely used of the three digital wireless telephone technologies (TDMA, GSM, and CDMA). It operates at either the $900 \mathrm{MHz}$ or $1,800 \mathrm{MHz}$ frequency band. It supports voice calls and data transfer speeds of up to $9.6 \mathrm{Kbit} / \mathrm{s}$, together with the transmission of SMS (Short Message Service). Hardware design parameters of the GSM modem are described below:

- Power supply: $3.2 \mathrm{~V} \sim 4.8 \mathrm{~V}$ DC

- The power consumption during sleep mode is $1 \mathrm{~mA}$.

- It operates in SIM900 Quad-band frequency bands, that is, GSM 850, EGSM 900, DCS 1800, and PCS 1900 SIM900 searches automatically the four frequency bands.

- Transmitting power is up to 2Watts at GSM 850 and EGSM 900, and 1Watt and DCS 1800 and PCS 1900.

- Temperature range for normal operation is $-30 \mathrm{C} \sim+80 \mathrm{C}$

- The GPRS data rate is a maximum of $85.6 \mathrm{kbps}$ downlink transfer and maximum of $42.8 \mathrm{kbps}$ uplink transfer. 


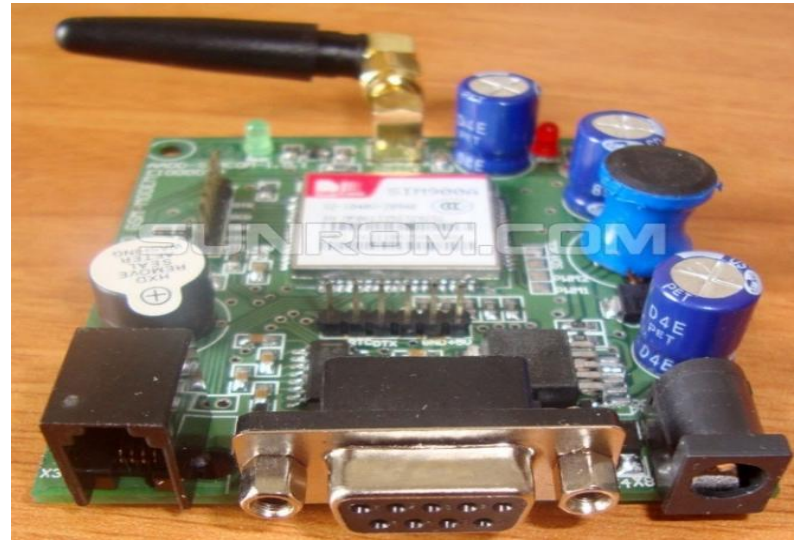

Figure 5: GSM Modem

\subsubsection{LCD Display}

A 20x4 LCD display is a very basic module and is very commonly used in various devices and circuits. These modules are preferred over seven segments and other multi segment LEDs. The reasons being: LCDs are economical; easily programmable; have no limitation of displaying special \& even custom characters (unlike in seven segments), animations and so on. A 20x4 LCD means it can display 20 characters per line and there are 4 such lines. In this LCD each character is displayed in $5 \times 7$ pixel matrix. This LCD has two registers, namely, Command and Data. This is a standard HD44780 controller LCD.

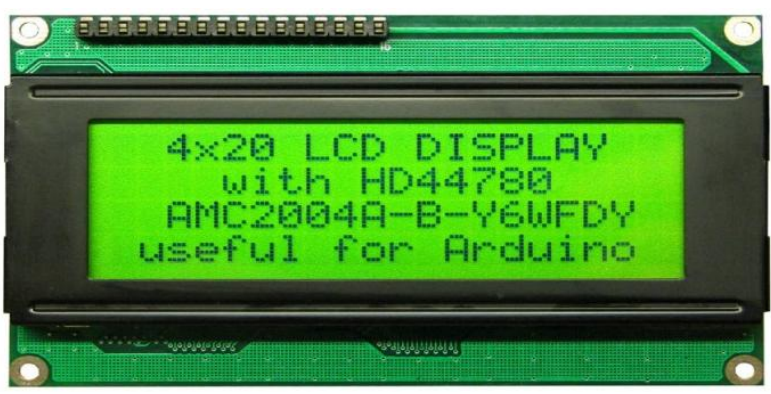

\subsection{Data storage part}

Figure 6: LCD display

SQL Server 2008 is used to store all the information received by GSM modem attached to the computer. SQL Server 2008 is used because of its high performance, scalability, security and availability. BAC, Speed, Latitude, Longitude, Time and date will be saved in the table that will be created in the database. Microsoft Visual Studio 2008 is used to produce SMS Application software that will be used to alert the nearest police post whenever the breach is detected. Using this SMS application software end user was able to receive SMS to any standard mobile phone about the event, position of the device, the date and time it happened. The positional data received is then converted to a human readable form using Reverse Geocoding technique. At the front end Visual basic will be used so as to make it easy for end users to view breach reports of vehicles.

\subsubsection{Finding Nearest Respective authority (Police post)}

The Spherical law of cosines is used to spot the location of a police station closest to a public bus that has encountered an event of over speeding or drunken driving. This formula is used generally for Computing great-circle distances between two pairs of coordinates on a sphere [11].

Before calculating a nearest point, the first route of the vehicle should be identified by a GPS receiver and stored in the database. The database has the table for the route where it checks before identifying the nearest police station. If the route is from Arusha to Dar the nearest police station will be in descending order from Geocode_ID 18 to 1 and if the Route is From Dar to Arusha the next station will be in ascending order from Geocode_ID 1 to 18 as shown in fig. 7 below. The location which will have the shortest distance is one close to the bus. The shortest distance is calculated by the spherical cosine rule Eq. (I).

Spherical law of cosines [5, 11]:

$\mathrm{d}=\mathrm{R} * \mathrm{a} \cos (\cos ($ lat 1$) \cdot \cos ($ lat 2$) \cdot \cos (\operatorname{lng} 2-\operatorname{lng} 1)+\sin ($ lat 1$) \cdot \sin ($ lat 2)).

Here, $d$ is the distance between two coordinates (lat1, lng2) and (lat2, lng2).

After receiving a new position, the nearest location name of the newly received position is found.

This is done by running the Spherical law of cosines in SQL query as below [11]:

"SELECT name, ( $3959 * \operatorname{acos}(\cos (\operatorname{radians}(' \mathrm{lat} 1)) *$ $\cos (\operatorname{radians}($ lat2 ) ) $* \cos (\operatorname{radians}(\operatorname{lng} 2)-\operatorname{radians}(' \operatorname{lng} 1 '))+$

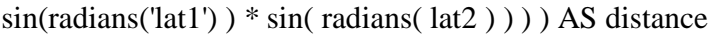

FROM geocode

HAVING distance $<5$

ORDER BY distance LIMIT 0, 1"

This query returns the name of the location which has the shortest distance with the new position.

\begin{tabular}{|c|c|c|c|c|}
\hline \multirow[t]{6}{*}{ jine } & 1 & UBUNGO_TERMINAL & $6.4659 \mathrm{~S}$ & 39.1159E \\
\hline & 2 & MANDELAKIBAHA & $6.4651 \mathrm{~S}$ & 38.5934E \\
\hline & 3 & MLANDIZI & $6.4305 \mathrm{~S}$ & $38.4431 \mathrm{E}$ \\
\hline & 4 & CHALINZE & $6.3818 \mathrm{~S}$ & $38.210 \pi$ \\
\hline & 5 & WAMI & $6.1234 \mathrm{~S}$ & $38.4655 \mathrm{E}$ \\
\hline & 6 & MKATA & $5.4707 \mathrm{~s}$ & $38.1739 \mathrm{E}$ \\
\hline \multirow{3}{*}{$7 x$} & 7 & SEGERA & 5.20075 & $38.3257 \mathrm{E}$ \\
\hline & 8 & KOROGWE & $5.0922 \mathrm{~S}$ & $38.2701 \mathrm{E}$ \\
\hline & 9 & MOMBO & $4.5315 \mathrm{~S}$ & $38.1749 \mathrm{E}$ \\
\hline \multirow{2}{*}{$\begin{array}{l}\text { ENGE } \\
\text { ataba } \\
\text { ables }\end{array}$} & 10 & HEDARU & 4.30255 & $37.5428 \mathrm{E}$ \\
\hline & 11 & SAME & 4.03595 & $37.4500 \mathrm{E}$ \\
\hline \multirow{2}{*}{$\begin{array}{l}\text { I Sys } \\
\text { | dbs }\end{array}$} & 12 & MWANGA & $3.4804 \mathrm{~S}$ & $37.4341 \mathrm{E}$ \\
\hline & 13 & HIMO & 3.23175 & $37.3252 \mathrm{E}$ \\
\hline \multirow{2}{*}{ | } & 14 & MOSHI & 3.20195 & $37.2034 E$ \\
\hline & 15 & BOMA_NG'OMBE & $3.2010 \mathrm{~S}$ & $37.0812 \mathrm{E}$ \\
\hline \multirow{3}{*}{ | } & 16 & KIA & $3.2512 S$ & $37.0356 \mathrm{E}$ \\
\hline & 17 & USA_RIVER & $3.2230 \mathrm{~S}$ & $36.5022 \mathrm{E}$ \\
\hline & 18 & ARUSHA_BUS ST... & $3.2208 \mathrm{~S}$ & $36.4100 \mathrm{E}$ \\
\hline
\end{tabular}

Figure 7: Geocode ID of Nearest police stations along Arusha - Moshi road 


\section{SYSTEM IMPLEMENTATION AND RESULTS}

The proposed system is implemented with one MQ-3 alcohol sensor and GPS receiver module for on board system. The system is successful implementation as proposed and the following is the snap shoot of the results.

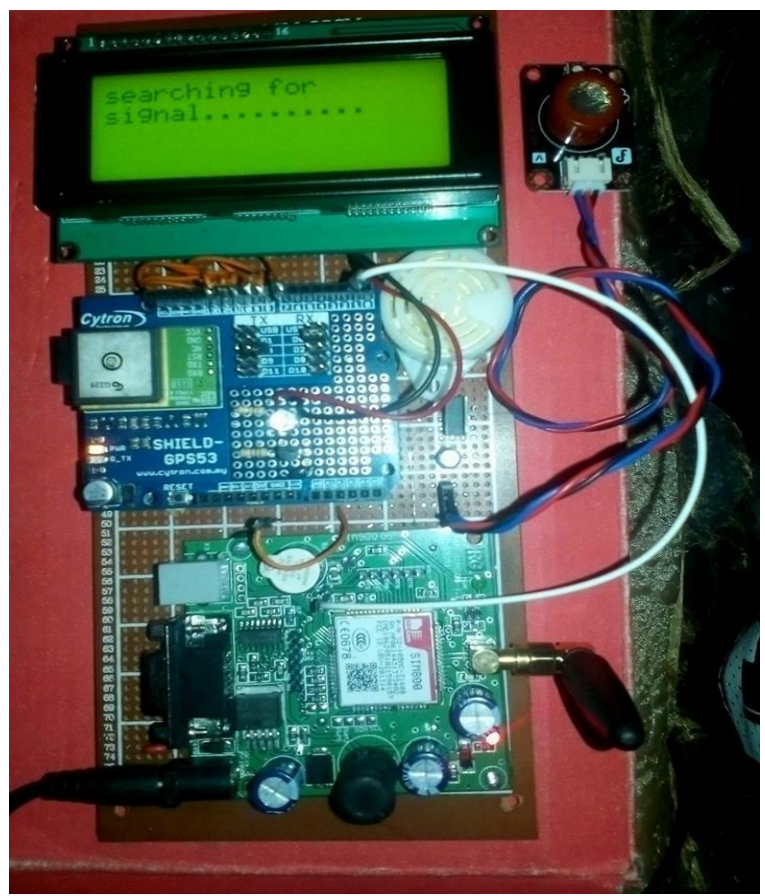

Figure 8: Snapshot of implemented system searching for signal

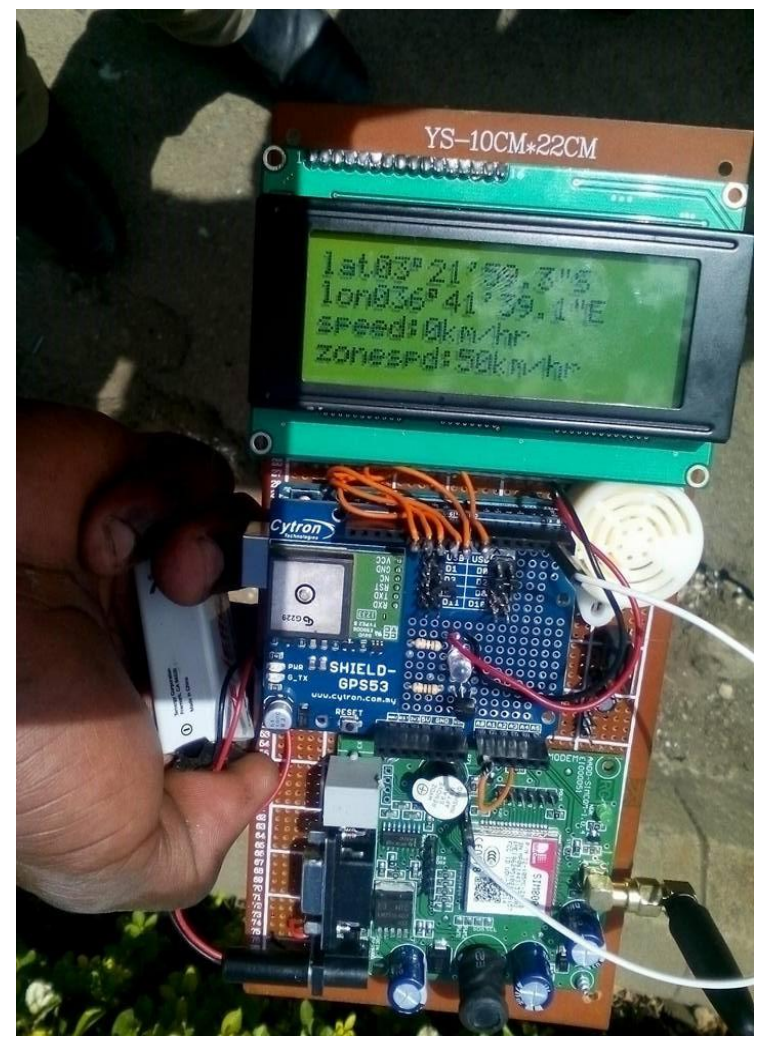

Figure 9: Snapshot of a system in action detecting a speed zone and display location and vehicle speed

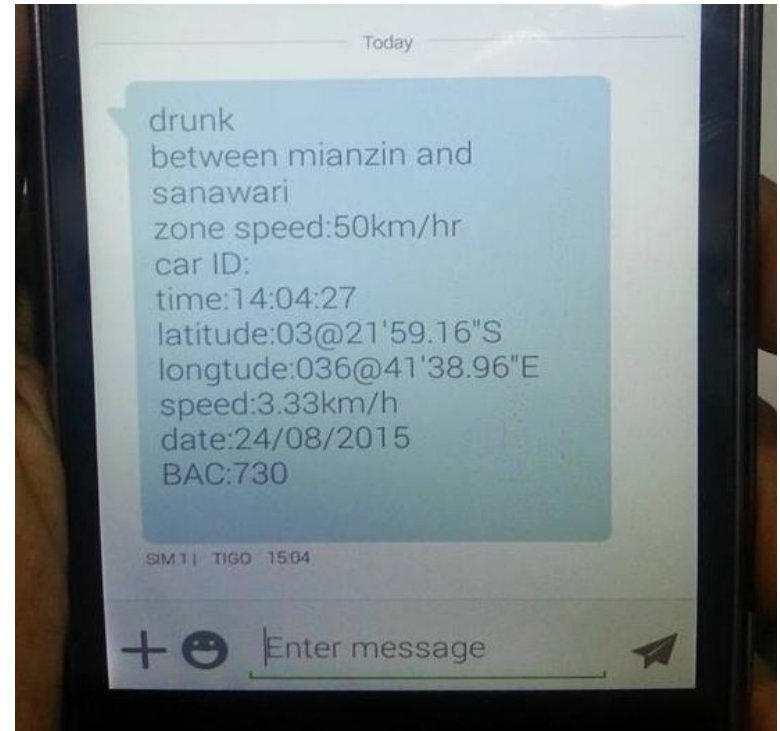

Figure 10: Message sent from the on-board unit to the respective authorities

\section{RESULTS AND DISCUSSION}

The developed system was installed in a small car for testing its performance. All parts of the system worked perfectly and the performance of GPS receiver was tested and proved to be efficient and accurate on providing a location coordinates and speed of a moving vehicle. As the vehicle enters into a $50 \mathrm{kph}$ zone, the GPS provides moving speed and at the same time Arduino controller commands LCD to display the limit and alert by blinking red LED. All of this functionality was performed within a fraction of second and all of the information was sent through GSM to the central database and maximum of 5 nearest police post from Arusha to Moshi were informed when any violation detected. In addition, power consumption of an on-board equipped parts is low; therefore, even the batteries can be used as a source of power and the system's performance will remain the same as when a grid electricity is used as a source of power. Since the existing approach of tracking over-speeding by using speed radar guns and manual alcohol checkup using breathalyzer is not efficient as it is only instituted to only accessible locations. Thus, after testing the prototype on the road, if our system will be implemented on public buses it is expected to improve transparency and accountability and therefore strengthening road safety. It will offer prompt warnings for immediate actions and provide forensic evidence that will facilitate prosecutions.

\section{CONCLUSION}

The adaptive vehicle speed monitoring system integrated with alcoholic detector was successfully implemented and tested using MQ-3 alcohol sensor and GPS receiver. The system is used to monitor a vehicle speed in different speed limits and driver's alcoholic status throughout the journey, and report to the respective authority (traffic police) immediately if any of the traffic rules violation is detected, especially over speed and drink driving. The system was tested in Arusha - Moshi road and proved good at what it was intended to do. Information regarding vehicle and driver behavior was collected and sent to a central database for any violation. The over speed and driver's alcoholic status information from different area within a specified road were collected and transmitted to a central database that makes these data available to law enforcers. If the proposed system 
implemented in public buses on major roads in Tanzania, then it would be potentially suitable as a solution to a road crashes resulting due to over speeding and drink driving.

\section{ACKNOWLEDGMENTS}

Authors would like to acknowledge The Nelson Mandela African Institute of Science and Technology under the School of Computational and Communication Science and Engineering for their support of this research.

\section{REFERENCES}

[1] WHO. Drinking and Driving: a road safety manual for decision-makers and practitioners. 2007 [cited 2015 Jan 25]; $\quad$ Available from: whqlibdoc.who.int/publications/2007/9782940395002_e ng.pdf?ua $=1$.

[2] Mutabazi, M. and H. Bishanga. SYSTEMS APPROACH TO THE ROAD SAFETY PROBLEM IN TANZANIA. in First Road Transportation Technology Transfer Conference in Africa. 2001. Arusha International Conference Centre, Tanzania

[3] National Audit Office Tanzania, A PERFORMANCE AUDIT REPORT ON THE MANAGEMENT OF TRAFFIC INSPECTIONS AND SPEED LIMITS IN TANZANIA, N.A. OFFICE, Editor. 2012, THE MINISTRY OF HOME AFFAIRS - TANZANIA POLICE FORCE AND THE MINISTRY OF WORKS: Tanzania.

[4] S Nyamawe, A. and E. C Mbosso, Road Safety: Adoption of ICT for Tracking Vehicles' Over-speeding in Tanzania. International Journal of Computer Applications, 2014. 96(16): p. 12-15.
[5] Hassan, K., A. Sam, and D. Machuve, A System for Monitoring and Reporting Excessive Passengers in Public Buses Case Study: Tanzania. International Journal Of Engineering And Computer Science, 2013. 2(8): p. 2342-2347.

[6] Bamasak, O., et al., Monitored Intelligent Car Speed Adaptation (MISA) System. International Journal of Electrical \& Computer Sciences, 2011. 11(3): p. 113203 7575 .

[7] Carsten, O.M. and F. Tate, Intelligent speed adaptation: accident savings and cost-benefit analysis. Accident Analysis \& Prevention, 2005. 37(3): p. 407-416.

[8] Rubini, R. and A. Uma Makeswari, OVER SPEED VIOLATION MANAGEMENT OF A VEHICLE THROUGH ZIGBEE. International Journal of Engineering Science \& Technology, 2013. 5(2)

[9] Mohamad, M.H., M.A.B. Hasanuddin, and M.H.B Ramli, Vehicle Accident Prevention System Embedded with Alcohol Detector. IJRECE, 2013. 1(4): p. 100-102.

[10] GPS_Datasheet. GPS Receiver with Active Antenna model \# 1141 Datasheet,. [cited 2015 12/7]; Available from: http://www.sunrom.com/p/gps-receiver-withactive-antenna.

[11] Hasan, K.S., et al. Cost effective GPS-GPRS based object tracking system. in Proceedings of the international multiconference of engineers and computer scientists. 2009. Citeseer. 